MECHANISMS OF PYRITE OXIDATION TO NON-SLAGGING SPECIES

Quarterly Report for the Period

April 1, 1996 - June 30, 1996

Grant DE-FG22-94PC94205

Prepared for

THE UNITED STATES DEPARTMENT OF ENERGY

Dr. Kamalendu Das

Project Manager

Morgantown Energy Technology Center

Morgantown, WV 26507-0880

Submitted by

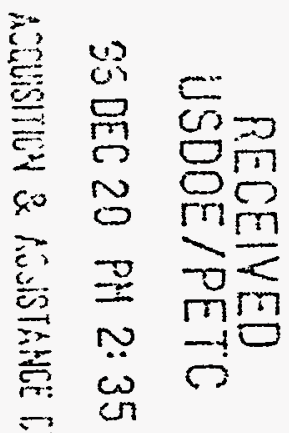

Mr. A. E. Jacob Akan-Etuk and Professor Reginald E. Mitchell

December 1996

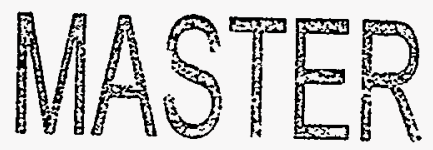

HIGH TEMPERATURE GASDYNAMICS LABORATORY Mechanical Engineering Department

Stanford University 


\section{DISCLAIMER}

Portions of this document may be illegible in electronic image products. Images are produced from the best available original document. 


\title{
MECHANISMS OF PYRITE OXIDATION TO NON-SLAGGING SPECIES
}

Quarterly Report for the Period

April 1, 1996 - June 30, 1996

Grant DE-FG22-94PC94205

Prepared for

\author{
THE UNITED STATES DEPARTMENT OF ENERGY \\ Dr. Kamalendu Das \\ Project Manager \\ Morgantown Energy Technology Center \\ Morgantown, WV 26507-0880 \\ Submitted by
}

Mr. A. E. Jacob Akan-Etuk and Professor Reginald E. Mitchell

This report was prepared as an account of work sponsored by the United States Government. Neither the United States nor the United States Department of Energy, nor any of their employees, makes any warranty, expressed or implied, or assumes any legal liability or responsibility for the accuracy, completeness, or usefulness of any information, apparatus, product or process disclosed, or represents that its use would not infringe privately owned rights. Reference herein to any specific commercial product, process, or service by trade name, mark, manufacturer, or otherwise, does not necessarily constitute or imply its endorsement, recommendation, or favoring by the United States Government or any agency thereof. The views and opinions of authors expressed herein do not necessarily state or reflect those of the United States Government or any agency thereof.

December 1996

High Temperature Gasdynamics Laboratory

Department of Mechanical Engineering

Stanford University

U.S. DOE Patent Clearance is NOT required prior to the publication of this document. 
PROJECT TITLE:

ORGANZATION:

CONTRACT:

REPORTING PERIOD:

REPORTED BY:
MECHANISMS OF PYRITE OXIDATION TO NONSLAGGING SPECIES

High Temperature Gasdynamics Laboratory

Stanford University

DOE DE-FG22-94PC94205

RESEARCH OBJECTIVES

A. E. Jacob Akan-Etuk and Reginald E. Mitchell

Phone: 415-725-2015

This document is the eighth quarterly status report on a project that is conducted at the High Temperature Gasdynamics Laboratory at Stanford University, Stanford, California and is concerned with enhancing the transformation of iron pyrite to non-slagging species during staged, low-NO $\mathrm{X}_{\mathrm{X}}$ pulverized coal (P. C.) combustion. The research project is intended to advance PETC's efforts to improve our technical understanding of the high-temperature chemical and physical processes involved in the utilization of coal. The work focuses on the mechanistic description and rate quantification of the effects of fuel properties and combustion environment on the oxidation of iron pyrite to form the non-slagging species magnetite. The knowledge gained from this work is intended to be incorporated into numerical codes that can be used to formulate anti-slagging strategies involving minimal disturbance of coal combustor performance. This project is to be performed over the three-year period from September 1994 to August 1997.

The project aims to identify the mechanisms of pyrite combustion and to quantify their effects, in order to formulate a general rate expression for the combustion of pyrite that accounts for coal properties as well as furnace conditions. Pyrite is introduced into a P. C. combustor as pure (extraneous) pyrite particles, pyrite cores within carbon shells, and inclusions in carbon matrices. In each case, once oxygen is transported to a pyrite particle's surface, the combustion of the pyrite involves the diffusion of oxygen from the particle's surface to its unreacted core and 
reaction of the diffused oxygen with the core. Consequently, a key feature of the program's approach to quantifying pyrite combustion is the sequential formulation of a reaction rate resistance network by isolating and quantifying the rate resistance induced by pyrite intraparticle mass transfer and pyrite intraparticle kinetics mechanisms.

Crucial to the project's methodology is the utilization of feed materials with carefully controlled properties to eliminate the uncertainty inherent in interpreting data obtained with natural coals (a consequence of the heterogeneity of natural coals). Homogeneous materials facilitate the modeling of specific combustion mechanisms without complications of non-uniform chemical composition and morphology.

In general, the project has the following objectives: 1) the characterization of the various mechanisms of intraparticle mass transfer and chemical reaction that control overall pyrite combustion rates and 2) the synthesis of the reaction rate resistances of the various mechanisms into a general rate expression for pyrite combustion. The knowledge gained from this project will be incorporated into numerical codes and utilized to formulate slagging abatement strategies involving the minor adjustment of firing conditions. Ultimately, the benefit of this research program is intended to be an increase in the range of coals compatible with staged, low- $\mathrm{NO}_{\mathrm{X}}$ combustor retrofits.

Following are specific objectives and deliverables associated with the six tasks of the research program:

\section{Task 1: Production and Characterization of Pyrite Feeds}

Objective: to produce and characterize pyrite feed materials of controlled particle size, carbon content, and carbon macroporosity.

\section{Deliverables:}

- Size-classified samples of pure pyrite particles.

- Size-classified samples of pyrite-laden synthetic bituminous coal particles of controlled macroporosity and mineral content. 
- Data on the physical properties of the feed materials: density, porosity, pore size distribution, and total surface area.

- Data on the chemical composition of the feed materials: component species, elemental composition, and proximate matter partitioning.

\section{Task 2: Pyrite Intraparticle Kinetics Resistance}

Objective: to perform combustion tests to quantify the reaction rate resistance introduced by pyrite intraparticle kinetics with respect to particle temperature and oxygen level.

\section{Deliverables:}

- A quench probe that can be used to extract particles from a laminar flow reactor at various residence times.

- An X-ray diffraction (XRD) procedure for the quantitative analysis of the solid residue from the combustion of pure pyrite samples.

- Measurements of the gas temperature and oxygen level in the flow reactor for the gaseous conditions to be used in our experiments.

- The results of combustion tests performed using pure pyrite particles to determine the minimum oxygen levels, maximum particle sizes, and appropriate extents of reaction compatible with negligible transport resistance for each stage of pyrite combustion: morphology and composition of reacted pyrite.

- The results of combustion tests performed using pure pyrite particles of small particle size to characterize intraparticle chemical kinetics resistance at various particle temperatures and oxygen levels: particle size distribution, morphology, and composition of reacted pyrite.

- An expression for the reaction rate resistance of the chemical kinetics of pyrite oxidation, including a kinetics rate coefficient expressed in Arrhenius form.

\section{Task 3: Pyrite Intraparticle Mass Transfer Resistance}

Objective: to perform combustion tests to quantify the reaction rate resistance introduced by pyrite intraparticle mass transfer with respect to particle size and temperature. 


\section{Deliverables:}

- The results of combustion tests using pure pyrite particles of small particle size to characterize intraparticle mass transfer resistance during the decomposition and solid oxidation stages of pyrite oxidation for various particle size classes and particle temperatures: particle size distribution, porosity, pore size distribution, total surface area, morphology, and composition of reacted pyrite.

- An expression for the reaction rate resistance introduced by intraparticle mass transfer during pyrite oxidation.

\section{Task 4: Carbon Matrix Kinetics Effects}

Objective: to perform combustion tests to characterize the effects of carbon matrix oxidation kinetics on the overall oxidation rate of pyrite inclusions.

\section{Deliverables:}

- A procedure for performing chemical analysis of the solid residue of the combustion of pyriteladen synthetic coal.

- The results of combustion tests using highly macroporous synthetic coal of small particle size, loaded with small pyrite inclusions to characterize the impact of the carbon chemical kinetics resistance for various particle temperatures: weight loss, morphology, and composition of reacted synthetic coals.

- A description of the effects of carbon matrix chemical kinetics resistance on the oxidation rate of pyrite.

\section{Task 5: Carbon Matrix Mass Transfer Effects}

Objective: to perform combustion tests to characterize the effects of carbon matrix mass transfer on the overall oxidation rate of pyrite inclusions.

\section{Deliverables:}

- The results of combustion tests using low-macroporosity synthetic coal loaded with small pyrite inclusions to characterize the impact of the carbon matrix mass transfer resistance: weight loss, morphology, and composition of reacted synthetic coals.

- A description of the effects of carbon matrix mass transfer resistance on the oxidation rate of pyrite. 


\section{Task 6: Rate Expression Formulation and Validation}

Objective: to formulate and validate an overall rate expression for pyrite combustion.

\section{Deliverables:}

- A mathematical expression for the pyrite chemical transformation rate formulated on the basis of reaction resistances of individual mechanisms.

- The results of combustion tests using a natural coal to validate the pyrite combustion rate expression with respect to coal particle size class, coal porosity, pyrite size class, pyrite content, gas temperature, and oxygen level: compositions of reacted coal samples. 


\section{CONTENTS}

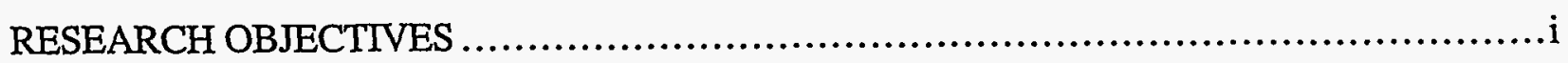

TECHNICAL PROGRESS DURING CURRENT QUARTER ............................. 1

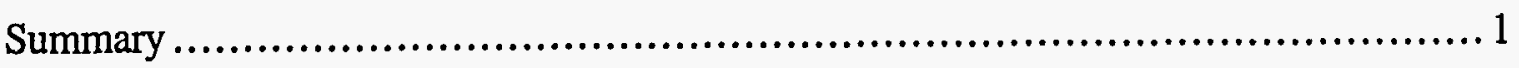

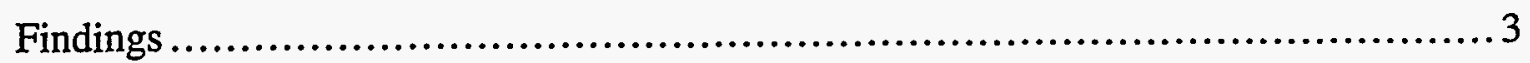

1.0 Task 6: Rate Expression Formulation and Validation ....................4

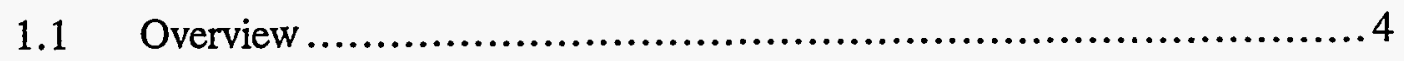

1.2 Conservation Equations ............................................. 4

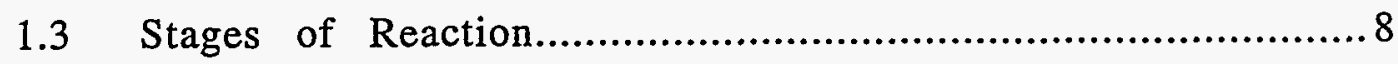

PLANS FOR NEXT QUARTER .........................................................

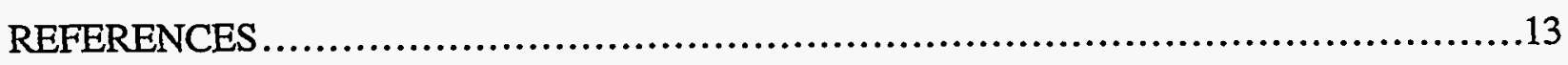




\section{TECHNICAL PROGRESS DURING CURRENT QUARTER}

\section{SUMMARY}

The information presented constitutes the report for the period April 1 to June 30, 1996. Formulation of a new pyrite oxidation model was embarked upon, using Srinivasachar and Boni's model [1] as a foundation. The model is intended to track the condensed-phase constituents of an oxidizing extraneous pyrite particle.

The model tracks the fate of a pyrite particle by solving relevant species, momentum, and energy equations. In the model, pyrite oxidation is demarcated into stages to facilitate the computation of required particle properties. The first stage is the preheat stage, during which the particle heats up to the decomposition temperature of pyrite $\left(\mathrm{FeS}_{2}\right)$. The preheat stage is followed by the pyrite decomposition stage, as the particle decomposes endothermally to pyrrhotite $(\mathrm{Fe} 0.877 \mathrm{~S})$. Once the particle temperature reaches the pyrrhotite softening point, any undecomposed pyrite transforms to troilite ( $\mathrm{FeS})$. The troilite formation stage is succeeded by the wustite $(\mathrm{FeO})$ formation stage. After wustite formation, magnetite $\left(\mathrm{Fe}_{3} \mathrm{O}_{4}\right)$ formation ensues.

At all times, intraparticle species conservation for the $i$ th species in the pyrite oxidation pathway is obtained by explicitly accounting for reaction rate resistances associated with reaction kinetics as well as mass transport. The conservation equation is as follows for species $i$ :

$$
\frac{d n_{i}}{d t}=-k_{i, t o t} n_{i} A_{p} C_{O 2, \infty}+k_{i-1, t o t} n_{i-1} A_{p} C_{O 2, \infty}
$$

with

$$
k_{i, t o t} \equiv \frac{1}{\frac{1}{k_{i}} \gamma+\frac{1}{k_{i, D}} v_{O 2, i}},
$$

where $n_{i}$ is moles of $i$ th species of oxidation pathway sequence within particle, $t$ is time, $k_{i, t o t}$ is rate coefficient for consumption of $i$ th species of pathway (comprising resolved coefficients of mass transport and kinetics), $A_{p}$ is particle area, $C_{O 2, \infty}$ is concentration of oxygen in environment, $k_{i}$ is chemical kinetics rate coefficient for consumption reaction of species $i, \gamma$ is particle external 
surface-to-volume ratio, $k_{i, D}$ is mass transfer rate coefficient for consumption reaction of $i$ th species, and $v_{O 2, i}$ is oxygen stoichiometric coefficient in consumption reaction of species $i$.

The particle trajectory for a vertically moving particle is provided by solving for the momentum balance between the gravitational and drag forces acting on the particle. The momentum balance is provided by the following equation:

$$
\rho_{p} \pi \frac{D_{p}^{3}}{6} \frac{d u_{p}}{d t}=\rho_{p} g \frac{D_{p}^{3}}{6}-\rho_{g} g \frac{D_{p}^{3}}{6}-3 \pi \mu D_{p}\left(u_{p}-u_{g}\right)\left[1+\frac{3}{16}+\frac{9}{160} R e_{D}^{2} \ln \left(2 R e_{D}\right)\right],
$$

where $\rho$ is density, $D$ is diameter, $u$ is velocity (positive up), $t$ is time, $g$ is acceleration of gravity, $\mu$ is gas viscosity, $R e_{D}$ is Reynolds number based on particle diameter and slip velocity, and subscripts $p$ and $g$ denote particle and gas, respectively.

Instantaneous particle temperature is obtained by ascribing rate of change of particle temperature to the net effect of chemical reaction, convection, and radiation. The unsteady energy equation is

$$
\begin{gathered}
\left(\sum_{i} n_{i} C_{p, i}\right) \frac{d T_{p}}{d t}=A_{p} h\left(T_{g}-T_{p}\right)+A_{p} \sigma \varepsilon\left(T_{w}^{4}-T_{p}^{4}\right)+\sum_{i}\left(-\Delta h_{r x n, i}\right) \frac{d n_{i}}{d t}, \\
\text { with } h \equiv \frac{N u \lambda}{D_{p}},
\end{gathered}
$$

where $n_{i}$ is moles of species $i, C_{p, i}$ is specific heat of species $i, T$ is temperature, $t$ is time, $A_{p}$ is particle area, $h$ is convection coefficient, $\sigma$ is Stefan-Boltzmann constant, $\varepsilon$ is particle emissivity, $\Delta h_{r x n, i}$ is heat of reaction for consumption reaction of species $i, N u$ is Nusselt number, $\lambda$ is thermal conductivity of gas, $D_{p}$ is particle diameter, and subscripts $p, g$, and $w$ denote particle, gas, and wall, respectively. 


\section{FINDINGS}

When Srinivasachar and Boni introduced the prevailing model of pyrite combustion, they cited the need for more accurate characterization of pyrite kinetics and transport parameters [1]. In their model, pyrite oxidation manifests the pathway

$$
\mathrm{FeS}_{2} \longrightarrow \mathrm{Fe}_{0.877} \mathrm{~S} \stackrel{\text { fragmentation }}{\longrightarrow} \mathrm{Fe}-\mathrm{S}-\mathrm{O}_{(\text {melt })} \longrightarrow \mathrm{Fe}-\mathrm{O}_{(\text {melt })} \longrightarrow \mathrm{Fe}_{3} \mathrm{O}_{4} \longrightarrow \mathrm{Fe}_{2} \mathrm{O}_{3},
$$

and occurs at a rate determined by kinetics and transport resistances. Subsequently, Stinivasachar et al. [2] provided additional pyrite conversion data that suggested that Srinivasachar and Boni's extraneous pyrite model [1] needed revisiting. Since the efforts of Srinivasachar et al., there has been little experimental work of fundamental nature to add to the understanding of extraneous pyrite thermochemistry. Consequently, the current research program was embarked upon to provide required pyrite conversion data.

In the current research program, time-resolved phase identifications of extraneous pyrite combustion products have been used to determine a pyrite oxidation pathway [3] different from that initially proposed by Srinivasachar and Boni. Tests at $1550 \mathrm{~K}$ gas temperature and $1 \%$ oxygen level indicate that, after transient thermal decomposition to form $\mathrm{Fe} 0.877 \mathrm{~S}$, pyrite oxidizes through the pathway

$$
\mathrm{FeS}_{2} \rightarrow \mathrm{FeS} \rightarrow \mathrm{FeO} \rightarrow \mathrm{Fe}_{3} \mathrm{O}_{4}
$$

with no evidence of significant fragmentation. Furthermore, tests at $12 \%$ oxygen level indicate that the rate-limiting step in the conversion of pyrite to magnetite changes with extent of reaction. The results of this research program, when coupled with observations of Srinivasachar et al.[2], necessitates the update of Srinivasachar and Boni's model [1].

This quarter, formulation of a new pyrite oxidation model was embarked upon, using Srinivasachar and Boni's model as a foundation. The model was intended to track the condensedphase constituents of an oxidizing extraneous pyrite particle. The modeling activity fell under the auspices of Task 6 of the research program. 


\subsection{TASK 6: RATE EXPRESSIONFORMULATIONAND VALIDATION}

\subsection{Overview}

The model tracks the fate of a pyrite particle by solving relevant species, momentum, and energy equations. In the model, pyrite oxidation is demarcated into stages, to facilitate the computation of required particle properties. The first stage is the preheat stage, during which the particle heats up to the decomposition temperature of pyrite $\left(\mathrm{FeS}_{2}\right)$. The preheat stage is followed by the pyrite decomposition stage, as the particle decomposes endothermally to pyrrhotite $(\mathrm{Fe} 0.877 \mathrm{~S})$. Once the particle temperature reaches the pyrrhotite softening point, any undecomposed pyrite transforms to troilite $(\mathrm{FeS})$. The troilite formation stage is succeeded by the wustite $(\mathrm{FeO})$ formation stage. After wustite formation, magnetite $\left(\mathrm{Fe}_{3} \mathrm{O}_{4}\right)$ formation ensues.

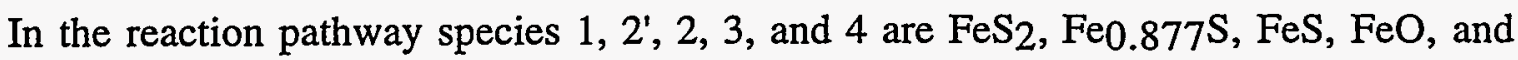
$\mathrm{Fe}_{3} \mathrm{O}_{4}$, respectively. These species can be either solid, liquid, or plastic, depending on particle temperature. Furthermore, for each step in the reaction pathway, there is a chemical reaction for the consumption of the $i$ th species of the pathway (except $\mathrm{Fe}_{3} \mathrm{O}_{4}$ ).

\subsection{Conservation Equations}

At all times, intraparticle species conservation for the $i$ th species in the pyrite oxidation pathway is obtained by explicitly accounting for reaction rate resistances associated with reaction kinetics as well as mass transport. The conservation equation is as follows for species $i$ :

$$
\frac{d n_{i}}{d t}=-k_{i, t o t} n_{i} A_{p} C_{O 2, \infty}+k_{i-1, t o t} n_{i-1} A_{p} C_{O 2, \infty}
$$

with

$$
k_{i, t o t} \equiv \frac{1}{\frac{1}{k_{i}} \gamma+\frac{1}{k_{i, D}} v_{O 2, i}},
$$

where $n_{i}$ is moles of $i$ h species of oxidation pathway sequence within particle, $t$ is time, $k_{i, t o t}$ is rate coefficient for consumption of $i$ th species of pathway (comprising resolved coefficients of 
mass transport and kinetics), $A_{p}$ is particle area, $C_{O 2, \infty}$ is concentration of oxygen in environment, $k_{i}$ is chemical kinetics rate coefficient for consumption reaction of $i$ th species, $\gamma$ is particle external surface-to-volume ratio, $k_{i, D}$ is mass transfer rate coefficient for consumption reaction of species $i$, and $v_{O 2, i}$ is oxygen stoichiometric coefficient in consumption reaction of species $i$.

During the preheat and pyrite decomposition stages, particle diameter remains at the initial value. After the particle reaches its softening temperature, instantaneous particle diameter (and therefore area) is calculated from particle composition and true density of constituent species.

The chemical reaction rate coefficient $k_{i}$ for each reaction $i$ is expressed as

$$
k_{i} \equiv A_{i} e^{-\frac{E_{i}}{R T}} \prod_{j} C_{j}^{v_{j, i}} C_{O 2, \infty}^{v_{02 i}-1},
$$

where $A_{i}$ and $E_{i}$ are Arrhenius pre-exponential factor and activation energy for reaction $i, C_{j}$ is local concentration of species $j$ involved in reaction $i$, and $v_{j, i}$ is stoichiometric coefficient of species $j$ per unit consumption of species $i$.

The diffusion rate coefficient $k_{i, D}$ is obtained by resolving the mass transport resistances external to and internal to the particle:

with

$$
k_{i, D} \equiv \frac{1}{\frac{1}{k_{i, D, e x t}}+\frac{1}{k_{i, D, i n t}}},
$$

where subscripts int and ext refer to external and internal to particle, respectively, $S h$ is Sherwood number, $D_{\mathrm{O} 2}$ is diffusion coefficient of oxygen in gas, and $D_{p}$ is particle diameter. The exact form of $k_{i, D, i n t}$ depends on the state of the particle internal structure, specifically pore structure and dispersion of reaction product within reactant. The Sherwood number for a sphere is calculated from the Ranz-Marshall equations [4] as

$$
S h=2\left(1+c R e_{D}^{0.5} S c^{0.33}\right),
$$

with

$$
0.30<c<0.35
$$


and

$$
R e_{D} \equiv \frac{\rho_{g}\left|u_{p}-u_{g}\right| D_{p}}{\mu}
$$

where $\operatorname{Re}_{D}$ is Reynolds number based on particle diameter, $S c$ is Schmidt number, $u$ is velocity, $\rho$ is density, $\mu$ is gas viscosity, and subscripts $p$ and $g$ refer to particle and gas, respectively. In the model, the preceding correlation for $S h$ is used, with $c$ specified at 0.30 Furthermore, the multicomponent diffusion coefficient of oxygen, $D_{O} 2$, is calculated from the equation of Fairbanks and Wilke [5]:

$$
D_{O 2}=\frac{1-\chi_{O 2}}{\sum_{k \neq O 2} \chi_{k} / D_{O 2, k}}
$$

where $\chi$ is mole fraction, $D_{O 2, k}$ is binary diffusion coefficient of oxygen, and subscript $k$ refers to component gas species $k$. Similarly, the multicomponent gas viscosity, $\mu$, is calculated using Wilke's mixing equation [6]:

$$
\begin{aligned}
\mu & =\sum_{k} \frac{\mu_{k}}{1+\frac{1}{\chi_{k}} \sum_{l \neq k} \chi_{l} \phi_{k l}}, \\
\text { with } \quad \phi_{k l} & \equiv \frac{\left(1+\sqrt{\frac{\mu_{k}}{\mu_{l}}} \sqrt[4]{\frac{M_{l}}{M_{k}}}\right)^{2}}{\frac{4}{\sqrt{2}} \sqrt{1+\frac{M_{k}}{M_{l}}}},
\end{aligned}
$$

where subscripts $k$ and $l$ denote gas component species $k$ and $l$.

The particle trajectory for a vertically moving particle is provided by solving for the momentum balance between the gravitational and drag forces acting on the particle. The momentum balance is provided by the following equation from Seinfeld [7]:

$$
\begin{gathered}
\rho_{p} \pi \frac{D_{p}^{3}}{6} \frac{d u_{p}}{d t}=\rho_{p} g \frac{D_{p}^{3}}{6}-\rho_{g} g \frac{D_{p}^{3}}{6}-3 \pi \mu D_{p}\left(u_{p}-u_{g}\right)\left[1+\frac{3}{16}+\frac{9}{160} \operatorname{Re}_{D}^{2} \ln \left(2 \operatorname{Re}_{D}\right)\right] \\
0.1<R e_{D}<2
\end{gathered}
$$


where $\rho$ is density, $D$ is diameter, $u$ is velocity (positive up), $t$ is time, $g$ is acceleration of gravity, $\mu$ is gas viscosity, $\operatorname{Re} D$ is Reynolds number based on particle diameter, and subscripts $p$ and $g$ denote particle and gas, respectively. Although Seinfeld recommends retaining only the first of the three terms in brackets when $R e_{D}$ is less than 0.1 , the difference is minor.

After the preceding momentum is solved to obtain the particle velocity, $u_{p}(t)$, the particle vertical position is obtained. The particle height, $Z_{p}(t)$, is obtained by integrating particle velocity with respect to time, $t$ :

$$
z_{p}(t)=z_{p}(0)+\int_{0}^{t} u_{p}(t) d t
$$

Instantaneous particle temperature is obtained by ascribing rate of change of particle temperature to net effect of chemical reaction, convection, and radiation. The unsteady energy equation is

$$
\left(\sum_{i} n_{i} C_{p, i}\right) \frac{d T_{p}}{d t}=A_{p} h\left(T_{g}-T_{p}\right)+A_{p} \sigma \varepsilon\left(T_{w}^{4}-T_{p}^{4}\right)+\sum_{i}\left(-\Delta h_{r x n, i}\right) \frac{d n_{i}}{d t}
$$

with

$$
h \equiv \frac{N u \lambda}{D_{p}},
$$

where $n_{i}$ is moles of species $i, C_{p, i}$ is specific heat of species $i, T$ is temperature, $t$ is time, $A_{p}$ is particle area, $h$ is convection coefficient, $\sigma$ is Stefan-Boltzmann constant, $\varepsilon$ is particle emissivity, $\Delta h_{r x n, i}$ is heat of reaction for consumption reaction of species $i, N u$ is Nusselt number, $\lambda$ is thermal conductivity of gas, $D_{p}$ is particle diameter, and subscripts $p, g$, and $w$ denote particle, gas, and wall, respectively. Similar to the Sherwood number, the Nusselt number is obtained from a Ranz-Marshall correlation [4]. The specific correlation used is

$$
N u \equiv 2\left(1+0.6 \operatorname{Re}_{D}^{0.5} \operatorname{Pr}^{0.33}\right)
$$

where $R e D$ is Reynolds number and $P r$ is Prandtl number (set equal to 0.7). Furthermore, the multicomponent thermal conductivity of the gas, $\lambda$, is calculated as follows from an equation by Wilke [6] that is almost identical to that for viscosity: 


$$
\lambda=\sum_{k} \frac{\lambda_{k}}{1+\frac{1}{\chi_{k}} \sum_{l \neq k} \chi_{l} \phi_{k l}} .
$$

In the preceding equations, gas properties are evaluated at a mean film temperature, $T_{m}$, defined using the one-third-two-thirds rule:

$$
T_{m} \equiv \frac{2 T_{p}+T_{g}}{3}
$$

\subsection{Stages of Reaction}

Preheat Stage (species present: $i=1 ; F e S_{2}$ )

During the preheat stage, solid pyrite is heated from room temperature to the pyrite decomposition temperature. There are no reactions during this stage, and the pyrite particle remains solid. The process is represented by the following chemical equation:

$$
\mathrm{FeS}_{2(s)} \longrightarrow \mathrm{FeS} 2(s)
$$

Since there are no chemical reactions, $k_{i}$ and, consequently, $d n_{i} / d t$ are nil for this stage. Furthermore, $D_{p}$ remains constant.

Pyrite Decomposition Stage (species present: $i=1,2$ '; FeS2, $\mathrm{Fe} 0.877 \mathrm{~S}$ )

Once the particle is heated to the decomposition temperature, $700 \mathrm{~K}$, the particle decomposes to form pyrrhotite and gaseous sulfur according to the reaction

$$
F e S_{2(s)} \longrightarrow F e_{0.877} S_{(s)}+\frac{1}{8} S_{8(g)}+\frac{1}{8} F e_{(g)}
$$


The decomposition temperature is specified as $700 \mathrm{~K}$, because from Jorgensen's data [8], $700 \mathrm{~K}$ is the temperature at which desulfurization commences. The reaction proceeds as an unreacted pyrite core with an inwardly advancing microporous pyrrhotite shell.

The reaction rate is limited by the rate of diffusion of liberated sulfur through the microporous pyrrhotite shell and across the boundary layer [2]. Consequently, the form of $d n i / d t$ specified in equation 1 does not apply. Rather, $d n i / d t$ equals nil, except for $i=1$ and 2 ':

$$
\frac{d n_{2^{\prime}}}{d t}=-\frac{d n_{1}}{d t}=-k_{1, t o t} C_{S 2} A_{p}
$$

with

$$
\begin{aligned}
k_{1} & \approx \infty, \\
k_{I^{\prime}, \text {,ext }} & \equiv \frac{S h D_{S 2}}{D_{p}}, \\
k_{l^{\prime}, D, \text { int }} & \equiv \frac{2 D_{S 2, \text { pore }} D_{f}}{\left(D_{p}-D_{f}\right) D_{p}},
\end{aligned}
$$

where $C_{S 2}$ is sulfur concentration at reaction front, $D_{S 2}$ is diffusion coefficient of sulfur in gas, $D_{S 2 \text {,pore }}$ is effective diffusion coefficient of sulfur through particle pores, $D_{f}$ is diameter of unreacted pyrite core.

The diameter of unreacted core is obtained from the following equation:

$$
\pi D_{f}^{2} \frac{d D_{f}}{d t}=\frac{1}{C_{l}} \frac{d n_{l}}{d t}
$$

where $C_{1}$ is concentration of species $l$ in the particle. The sulfur concentration at the reaction front is specified as the equilibrium concentration of sulfur.

During the pyrite decomposition stage, particle diameter remains constant. Particle emissivity is specified as that of pyrrhotite. The pyrite decomposition stage ends when the particle temperature reaches the softening point. 
Troilite Formation Stage (species present: $i=1,2$, 2; $\mathrm{FeS}_{2}, \mathrm{Fe} 0.877 \mathrm{~S}, \mathrm{FeS}$ )

Troilite formation begins when the particle temperature reaches the softening point of pyrrhotite. The $\mathrm{FeS}-\mathrm{FeO}$ has a eutectic at $1190 \mathrm{~K}$, and this temperature is taken as the particle softening point. After softening, any remaining pyrite decomposes to form troilite and sulfur according to the reaction

$$
\mathrm{FeS}_{2}+\mathrm{O}_{2} \longrightarrow \mathrm{FeS}+\frac{1}{8} \mathrm{~S}_{8(\mathrm{~g})}+\mathrm{O}_{2}
$$

During troilite formation, $d n_{i} / d t$ is nil except for $i=1$ and 2. Also, Reaction R1A is no longer operative. Intraparticle mixing is sufficiently great to eliminate radial gradients in composition. Consequently, in Equation 4, $k_{i, D}$,int is set to infinity for $i=1,2$; internal oxygen level is assumed to be proportional to the oxygen level at the surface. The troilite formation stage ends when all of the pyrite is consumed.

Wustite Formation Stage (species present: $i=2$ ', 2, 3; Fe0.877 $, \mathrm{FeS}, \mathrm{FeO}$ )

After all of the pyrite is consumed, wustite formation occurs as soon as troilite is formed. (The analog of wustite formation is formation of iron oxide, $\mathrm{Fe}_{1-\mathrm{x}} \mathrm{O}$, from pyrrhotite, $\mathrm{Fe} 0.877 \mathrm{~S}$.) Troilite and pyrrhotite are oxidized to form wustite and sulfur monoxide according to the reactions

$$
\begin{aligned}
& \mathrm{FeS}+\mathrm{O}_{2} \longrightarrow \mathrm{FeO}+\mathrm{SO} \\
& \text { and } \\
& \mathrm{Fe}_{0.877} \mathrm{~S}_{(s)}+\mathrm{O}_{2} \longrightarrow \mathrm{Fe}_{1-\mathrm{X}} \mathrm{O}+\mathrm{SO}
\end{aligned}
$$

During wustite formation, $d n_{i} / d t$ is nil except for $i=2 ', 2$, and 3. Furthermore, intraparticle mixing is sufficiently great to eliminate radial gradients in composition. Thus, in Equation $4, k_{i, D, i n t}$ is set to infinity for $i=1,2$ ', 2 , and 3 , and internal oxygen level is assumed 
to be proportional to the oxygen level at the surface. The wustite formation stage continues until all of the pyrite is consumed.

Magnetite Formation (species present: $\mathrm{i}=3,4 ; \mathrm{FeO}, \mathrm{Fe}_{3} \mathrm{O}_{4}$ )

Wustite oxidation to form magnetite commences as soon as all of troilite and pyrrhotite is consumed. The transformation is described by the reaction

$$
\mathrm{FeO}+\frac{1}{6} \mathrm{O}_{2} \longrightarrow \frac{1}{3} \mathrm{Fe}_{3} \mathrm{O}_{4}
$$

During magnetite formation, $d n_{i} / d t$ is nil except for $i=3$, and 4 . In addition, intraparticle mixing is sufficiently great to eliminate radial gradients in composition. Therefore, in Equation 4, for both $i=3$ and $4, k_{i, D \text {,int }}$ is set to infinity and internal oxygen level is assumed to be proportional to the oxygen level at the surface. Magnetite formation continues until all wustite is depleted. Subsequently, the magnetite cools and become more solidified. 


\section{PLANS FOR NEXT QUARTER}

Next quarter's emphasis will be placed on the quantitative characterization of the reaction rate resistance introduced by intraparticle kinetics during the oxidation of iron pyrite. The activities to support this aim will span Tasks 2 and 6. Following is a description of the planned activities for the July 1 to September 30, 1996 reporting period:

\section{Task 2: Pyrite Intraparticle Kinetics Resistance}

- Intraparticle reaction resistance will be calculated from obtained composition data using the numerical model to be implemented (Task 6).

\section{Task 6: Rate Expression Formulation and Validation}

- A numerical model will be implemented to describe pertinent species, momentum, and energy balances during pyrite oxidation. 


\section{REFERENCES}

1. Srinivasachar, S. and Boni, A., Fuel, 68, 1989, p. 829.

2. Srinivasachar, S., Helble, J. J., and Boni, A. A., Prog. Energy Combust. Sci, 16, 1990, p. 281.

3. Akanetuk, A. E. J. and Mitchell, R. E., Paper No. 96F-051, WSS/CI Fall Mtg., Los Angeles, CA, October 1996.

4. Ranz, W. E. and Marshall Jr., W. R., Chem. Eng. Prog., 48, 1952, p. 173.

5. Fairbanks, D. F. and Wilke, C. R., Industrial and Engineering Chemistry, 42, 1950, p. 471.

6. Wilke, C. R., Journal of Chemical Physics, 18, 1950, p. 517.

7. Seinfeld, J. H., Atmospheric Chemistry and Physics of Air Pollution, John Wiley \& Sons, New York, 1986.

8. Jorgensen, F. R. A., Trans. Inst. Min. Metall. Sect. C, 90, 1981, p. 1. 